\title{
Recruitment and Hiring Process Configuration Plan for Kalinga State University
}

\author{
Jayhan C. Sarne
}

Kalinga State University, Philippines

Received: 05 Oct 2020; Received in revised form: 20 Dec 2020; Accepted: 22 Dec 2020; Available online: 31 Dec 2020

C2020 The Author(s). Published by Infogain Publication. This is an open access article under the CC BY license

(https://creativecommons.org/licenses/by/4.0/).

\begin{abstract}
In an age of pervasive machine presence, the existence of Information and Communication Technology is embedded in this fact (ICT). The academic community today is conscious of the benefits of ICT, too. This is not only from the point of view of education and research activities, but also from the point of view of industry, which uses ICT to support other business functions, such as administrative, operational, human resources, accounting, etc. The module SAP Human Resources Management (HRM) improves the work process and data management within the enterprise HR department. Using this module, the right to employ an individual to assess one's performance, administer promotions, rewards, handle payroll, and other related HR activities is processed. This SAP ERP HRM module is used to handle the task of managing the information and task flow of the most valuable resource, i.e. human resources. The purpose of this research was to establish a plan for the configuration of human resources for the implementation of the Kalinga State University ERP system.
\end{abstract}

Keywords-Human Resources, Human Resources Management, HCM, Accelerated SAP, Enterprise Resource Planning.

\section{INTRODUCTION}

In an age of pervasive machine presence, the existence of Information and Communication Technology is embedded in this fact (ICT). The academic community today is conscious of the benefits of ICT, too. This is not only from the viewpoint of education and research activities, but also from the business side, which uses ICT to facilitate other business functions, such as administrative, operational, human resources, accounting, etc.

In its business functional areas such as management, manufacturing/operations, marketing, finance/accounting, research \& development (R\&D), and management information system (MIS), each company often seeks to implement creative techniques and processes to achieve and retain competitive advantage in the modern business environment. Tan \& Nasurdin (2011) said that corporate creativity is a critical tool for businesses to retain their competitive place in the market world.

Higher education has been heavily affected by technology in recent years and is required by governments to enhance performance and productivity. With increased demands and expectations from students, faculty, administrative staff and governments, along with reduced government funding, highly competitive education environments have overstretched universities worldwide to implement new strategies to boost their performance. Consequently, in order to help them cope with this changing climate, the higher education sector has switched to Enterprise Resource Planning (ERP) systems.

The ERP System is a software solution that incorporates business processes and information into a single system to be shared within an enterprise. Although ERP originated from manufacturing and production planning frameworks used in the manufacturing industry, ERP extended its reach to other 'back-office' functions in the 1990s, such as human resources, finance and production planning (Nieuwenhuyse, et.at, 2011).

The extension of ERP into the functions of Human Resources played a critical role in the feasibility of the academic component of Human Capital Management (HCM). Human Capital Management or Management of Resources (HRM) is the organizational role that deals with employee- 
related problems such as compensation, recruiting, performance management, organizational growth, engagement of employees, communication, administration, and training.

A well-known and effective ERP solution is SAPERP program. It is an interconnected framework where information is exchanged by all the SAP modules. In this method, transactions are performed automatically based on the processes specified. In data processing, SAP stands for Structures, software and products. SAP offers financial, manufacturing, logistics, distribution, and other solutions. $\mathrm{SAP}$, as a method, is a product of the SAP AG. (Bharne and Gulhane, 2012)

Higher education ERP programs are being developed in the direction of supporting key administrative and academic resources. Minimal student administration (enrolment procedures and student enrolment, student financial support, student data), human resource management (employee monitoring) and finance are generally supported at the center of such a system (accounting, payments, investments, budget). Any additional software add-ons may be included, such as asset management (contracts, loans, grants, etc or tracking of student and institutional development services (Rani, 2016).

Universities' key reasons for implementing ERP solutions are replacing outdated systems, enhancing customer service and changing business processes, modernizing information systems, improving management, retaining competitiveness, increasing operational performance, and complying with regulatory enforcement. The advantages of ERP solutions are that it is good for one's career to be part of an ERP project; the new systems provide better facilities for faculty, things, and students; streamlined administrative, academic, and student data; internationally accessible university data over the Internet; and less expense and risk than legacy systems are involved in the new systems (Edgar Fleisch, et.al, 2004).

According to King (2002), the key benefits of ERP in HEIs are (1) enhanced access to knowledge for institution planning and management, (2) improved facilities for professors, students and employees, (3) reduced business risks, and (4) increased revenue and reduced costs due to improved performance (Sabau, et.al, 2009).

Through implementing advanced Human Resource Management Programs, academies started electronically automating many of these procedures to eliminate manual tasks. In order to build and sustain an integrated HRMS, HR executives rely on internal or external IT professionals. Human Resource Management Systems have made it possible to improve administrative control of such systems more and more.

One of the universities that never stops acknowledging new technologies for the advancement of services for its clients is Kalinga State University.

\section{METHODOLOGY}

This chapter discusses the system development methodology, scope and delimitation of the study, data gathering techniques, and sources of data.

\section{Software Development Methodology}

The proponent suggested configuration as a software development technique using the Accelerated SAP (ASAP).

For the implementation of the SAP project, there are various project methodologies available, but the researcher used the methodology of accelerated SAP (ASAP) software creation for this analysis. It is a systematic approach for the deployment and continuous optimization of SAP applications efficiently. It is a comprehensive, business-oriented framework which enables one to flexibly plan implementation projects. This kit consists of three components: ASAP Roadmap, Instruments, and Training and R/3 Services.

The ASAP Roadmap breaks the method of implementation into the five stages shown in Figure 1. At each stage of the Roadmap structure, the documentation stores include recommendations on the implementation of SAP software and links to helpful resources and accelerators.

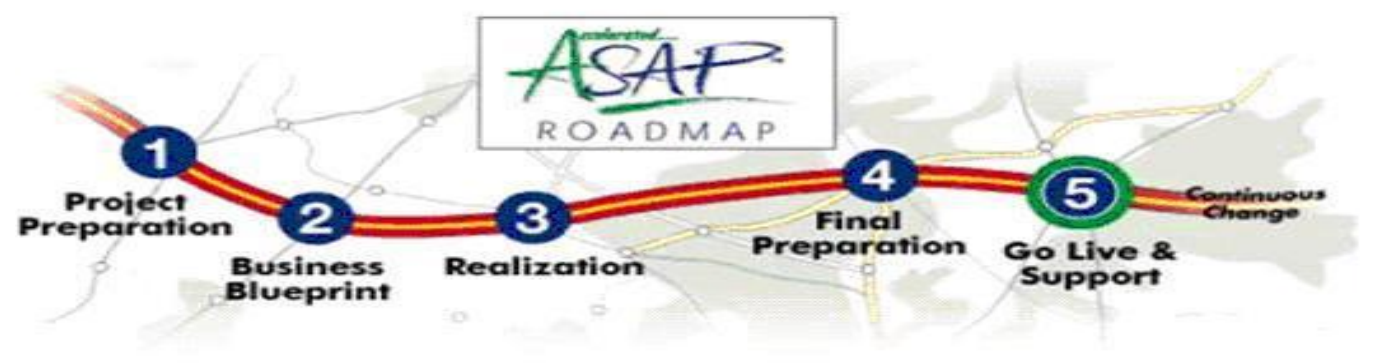

Fig.1: ASAP Roadmap 


\section{Data Gathering Techniques}

In collecting data needed for the proposed study and its reporting, this analysis used the following techniques:

With an interview. The researcher conducted a series of interviews with the staff of Kalinga State University Human Resources to obtain the appropriate information to understand the University's current human resources management processes. This approach was used because it was the most reliable way to collect data from KSU employees and management.

Analysis Paper. The researcher reviewed and examined the current documentation relating to the human resources of KSU in order to expand the researcher's knowledge of ERP and HR processes. Observation. Note. This was done as part of the study of the current procedures involved in the human resource unit's human resources processes.

\section{Sources of Data}

The primary data sources in this analysis were the data collected from the interview with employees of the Human Resources Unit, MIS employees and findings on current business practices, policies, company protocols related to the field of Human Resources.

Document analysis on the records and forms produced by Human Resources workers, such as Personal Data Sheet, BC-CSC form, KSS form, PDS form and SALN form, was the secondary source of data.

In the Human Resources Department, the observation conducted transactions involved

\section{RESULTS AND DISCUSSION}

This chapter presents the results of this study regarding the configuration plan of the Kalinga State University SAP Human Resources Module (KSU). It also addresses the existing KSU-Human Resources Department structure, problems, issues, and configuration specifications.

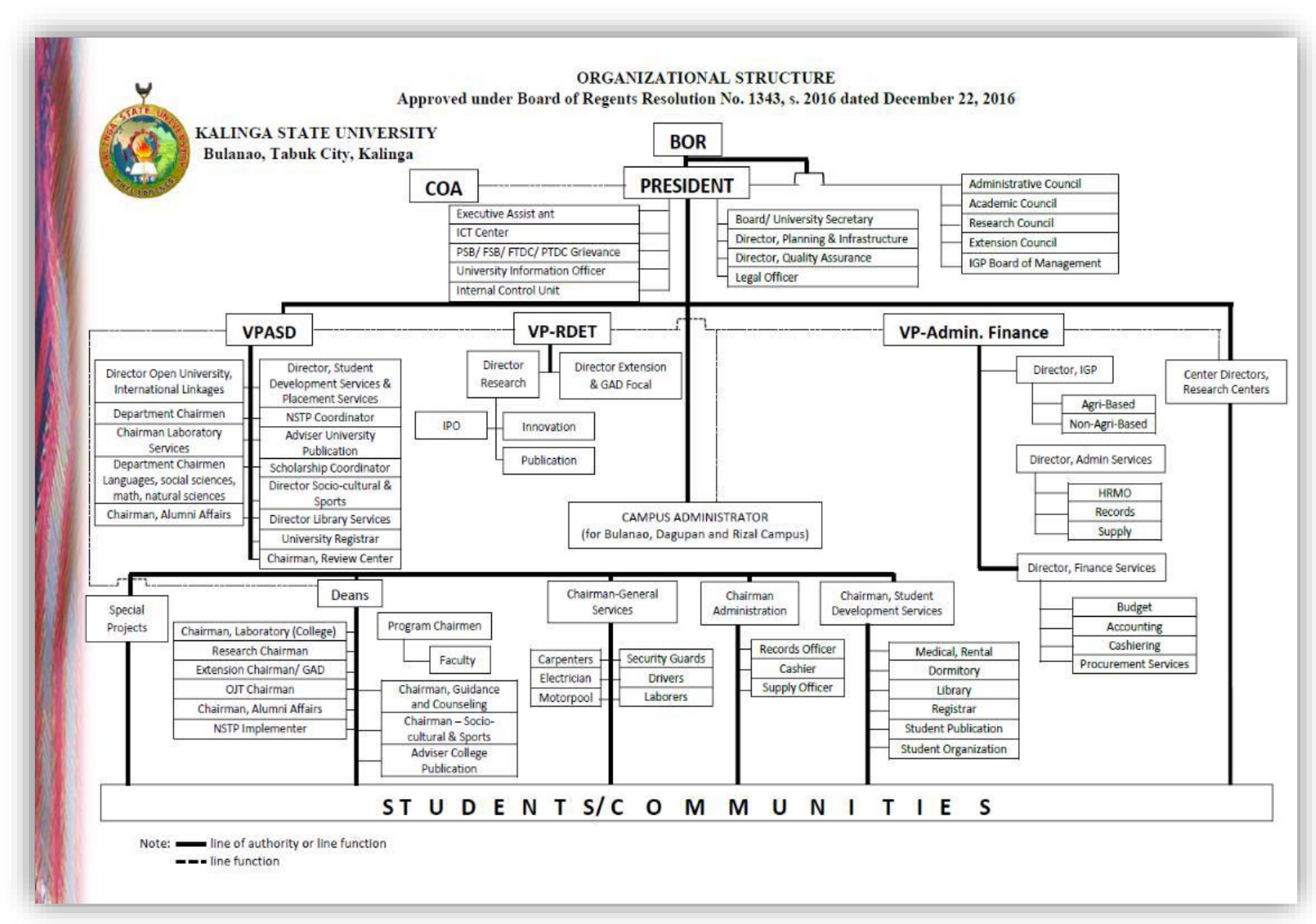

Fig.2: KSU As-Is Organizational Chart 


\section{Configuration Requirements of SAP HR at KSU}

Kalinga State University (KSU) consists of three (3) campuses, namely the Bulanao Campus, the Dagupan Campus and the Rizal Campus. The Office of Human Resources Management (HRMO) is situated on the main campus in Bulanao. All documents in the HRMO are as practiced, manually sorted, put in a folder and filed in a cabinet of the filing system. At present, no human resource application framework is being used at KSU to meet the existing needs of the HRMO.
On Structure of Organization. The key focus of this analysis is the Human Resource Management Office (HRMO). As seen in Figure 2, it comes under the VicePresident for Administration and Finance department. Rosalinda B. Soriano heads the HRMO. The HRMO Clerk is under her stewardship, in the person of Rizalyn Valdez. These two workers

Working hand in hand to provide all KSU staff with the best human resources support. For the HRMO organizational structure at KSU, please refer to figure 3.

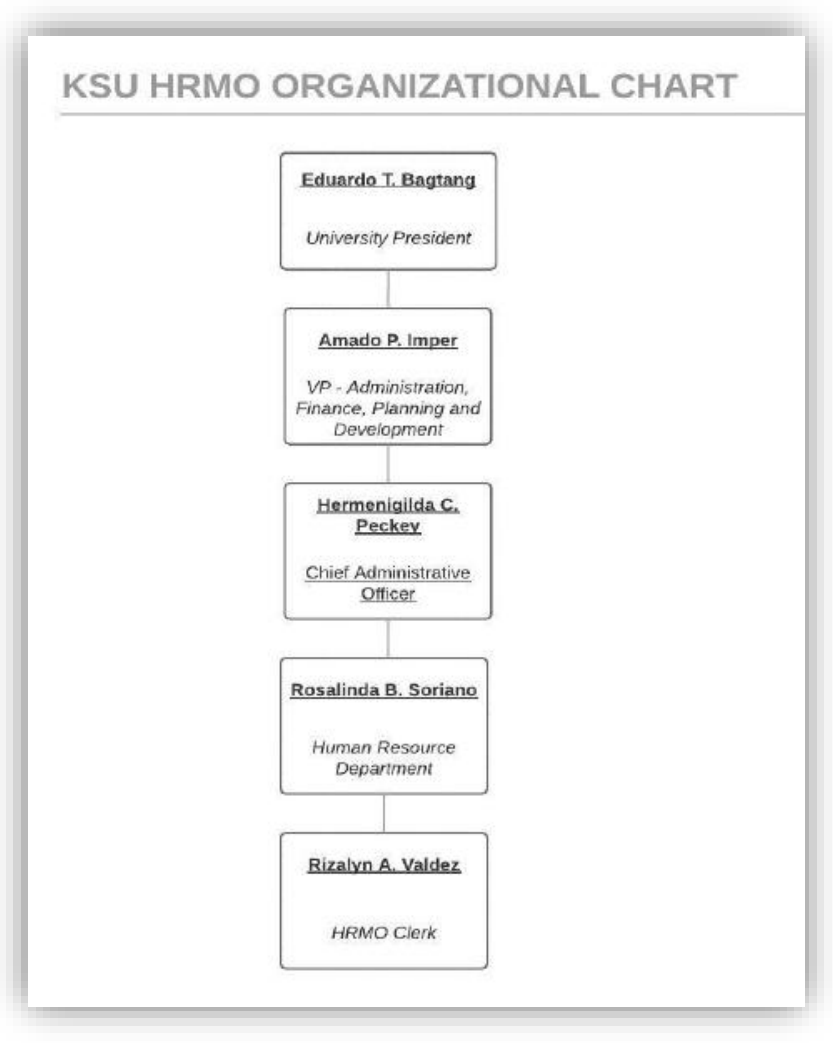

Fig.3: HRMO Organizational Chart

The duties of the Human Resource Management Office are as follows:

Recruiting. This role includes the request for new staff; the disclosure of vacancies and the recruiting of staff to fill the vacancy; the screening process; and the recruitment of new staff.

Promotion and Place. This duty includes the development of promotion and selection criteria and guidelines and the recommendation of the best eligible candidate (s).

Accounting for Staff. The aim of this role was to generate reports and updates on the talent population; to track employee participation; and to prescribe disciplinary action whenever appropriate.

In addition, KSU's Human Resource Management Office has 3 main procedures, the following are: manpower planning; managing staff; and managing time. A visual representation of the core processes is shown in Figure 4. 


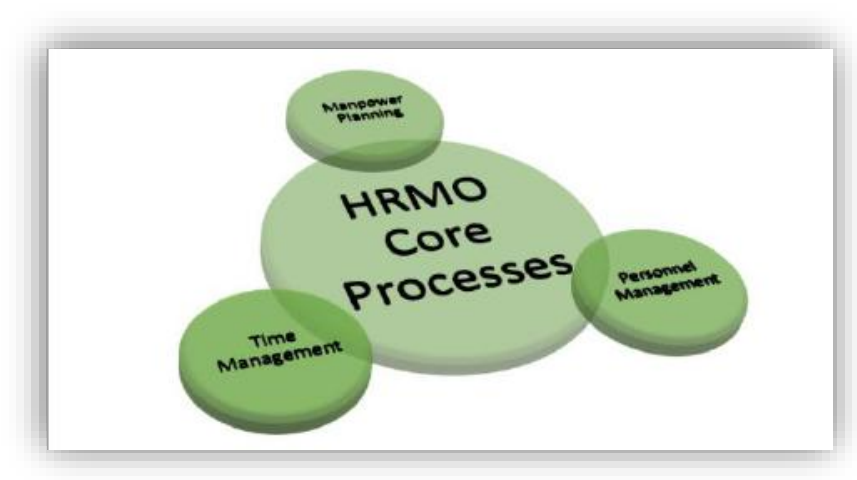

Fig.4: KSU HRMO Core Processes

Manpower preparation is the first of the core processes. Manpower planning, also known as human resources planning, consists of putting the right number of people in the right place and time to meet KSU objectives and goals, with the right skills and experiences.

The requisitioning department or office recognizes the appropriate workers in its respective department at KSU as a standard and sends a request form to notify the HRMO. Then, depending on the request of the requesting agency or office, the HRMO advertises the work vacancies.

The preparation for personnel starts once the position is identified. For potential candidates, a review of the latest workforce backup pool is also inevitable, particularly for urgent resource requirements. HRMO opens the vacancy to external outlets such as walk-ins, and or referrals if there are no eligible applicants from the pool. Similarly, the same process is followed by internal and external applicants.

KSU-HRMO includes the following documents from its internal and external applicants: Application Letter; CV; Diploma; Official Transcript of Records (OTR); Certificate of Eligibility or License; Training Certificates; and other required documents to be sent to the Office of Human Resource Management as requested.

The following steps will be facilitated by HRMO staff upon receipt of the requested documents from the applicants; initial interview; encoding of applicant(s) information; short listing of qualified interviewee(s); filing of applicant documentation.

The initial panel interview and assessment will be performed by the Director of Human Resource Management Office with the Deans of various colleges until all records are reviewed.

If the applicant has successfully passed the panel interview, the President's interview is scheduled. Following an interview with the President of the University, the HRMO Clerk encodes the applicants' personal data in the Personal Data Sheet (PDS) form, updates the applicants' shortlists and files the applicants' shortlists according to priority, depending on the applicant's qualifications and KSU needs. The Chief Administrative Officer and the KSU President evaluate and authorize the final list of applicants for a job/position.

In order to complete the following steps, paperwork and new recruit criteria, the successful applicant is then advised: 201 File; Registration of biometrics and safe company ID. The Records Officer will plan and issue the employment contract or appointment to the newly hired employee after the first three measures have been completed.

The final process of his/her application is to receive a confirmation of the teaching load from the dean or supervisor of the department where he/she is assigned if the newly hired is a teaching staff. He/she will also be introduced to key stakeholders and will. For the description of the manpower pooling process, refer to figure 5 .

Personnel Management is the second HR core process at KSU. Personnel Management is often characterized as the acquisition, use and maintenance of a happy workforce. It is a vital field in the management of human resources that is mainly concerned with the health of workers at work and their working relationship within the company.

Recordkeeping is a central feature of Personnel Management. In KSU, the personal records and mandatory transactions of all employees are properly and religiously registered while still in operation. Updated information and records of employees are crucial to effectively controlling the movement of employees; thus, personnel management is an important HR core process 


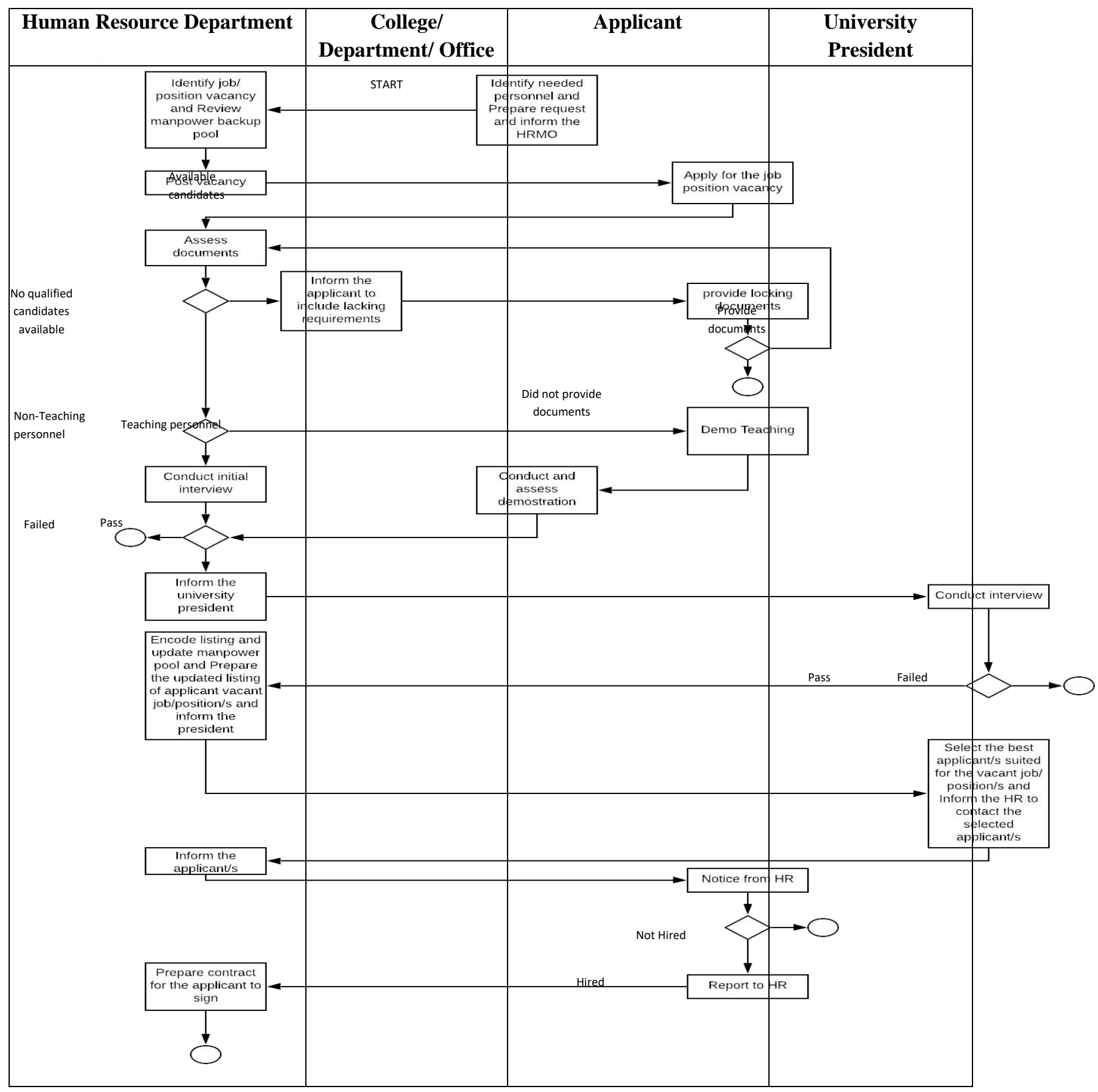

Fig.5: Manpower Planning of KSU (As-Is)

KSU does not currently have any system or program that handles its personnel records. All documents are manually transmitted, such as preserving the personal details of the employee, hiring dates, and other information relevant to the employee.

Other procedures, such as leaf filing, are apparently handled manually and maintained by the department of the record division. Also, employee clearance needs to be achieved manually by the employee when leaving the company via the clearance form available at the office of HRMO. By physically collecting the signatures, as shown in Figure 6, all appropriate signatories are obtained. 


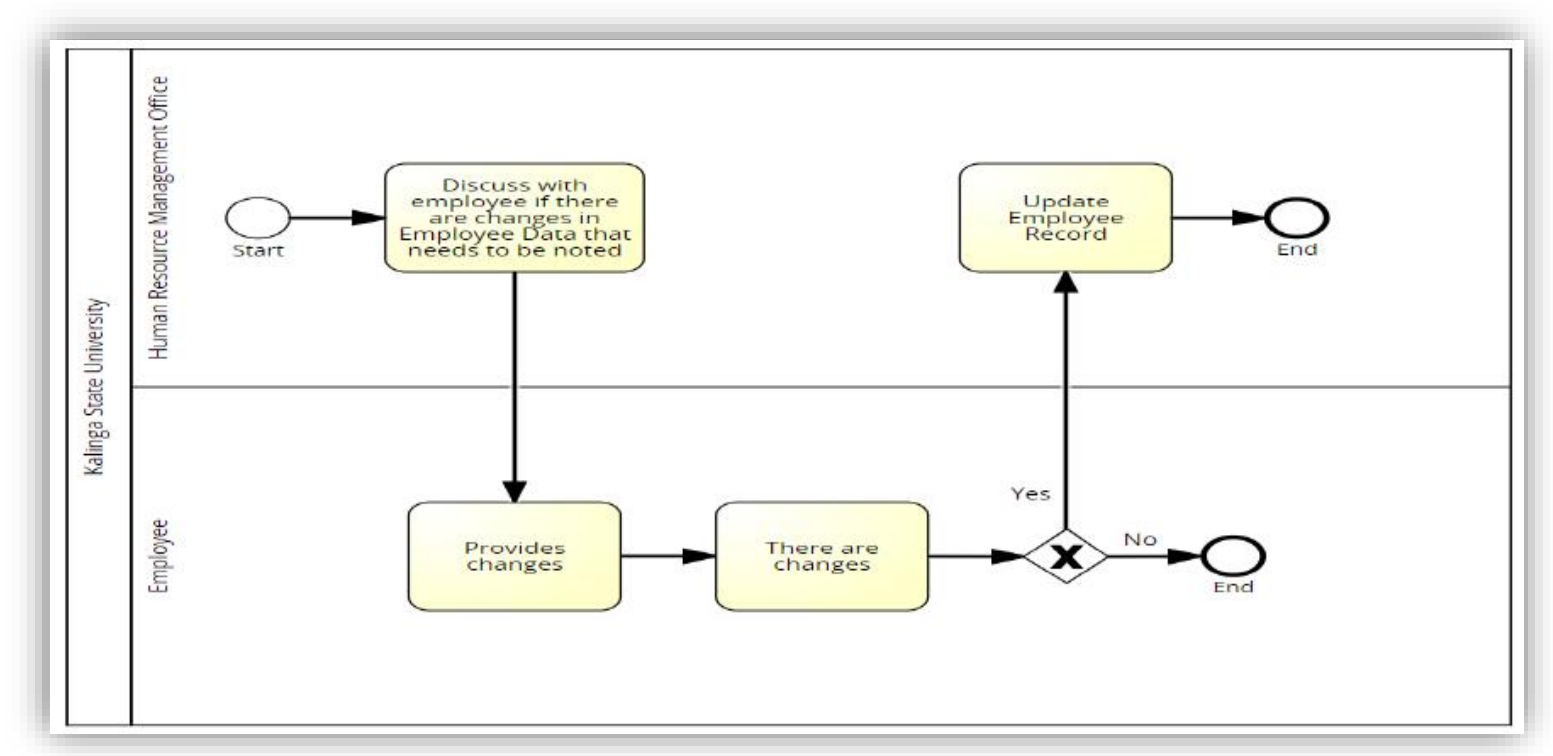

Fig.6: KSU Personnel Management (As-Is)

Time Management is the third HR core operation. Time management is one of the key components of any enterprise because, along with the work done, it is important to preserve time. This helps a company in a project to assess profit and loss, human expense, and track time reservations, etc.

When an employee, such as a teaching fellow, is employed, a workload is provided by his or her immediate boss, the Dean. The workload includes the subject he/she will teach, the assignment of rooms and the day and time planned. For KSU staff, the daily working hours are 8 hours a day from 8:00 a.m. to 5:00 p.m. with 5 days of work from Monday to Friday.

Both workers are supplied with the biometrics system to log-in and log-out from work. It is expected that all KSU employees will arrive on time. If the biometrics failed for whatever reason to ensure that workers work within the mandated hours, each college or department is required to maintain a log book where employees log-in and log-out.

At the start of regular work hours, all workers are supposed to be present and ready to work. At the end of their allocated working hours, they are supposed to finish their respective work as well.

KSU only allows a grace period of a maximum of 15 minutes until an employee is deemed tardy. It manually performs the measurement of working hours. The HR clerk measures and cross-checks the biometrics scheme and the logbook from each department and college in order to obtain the actual working hours rendered by an employee. She will forward the time sheet reports to the Chief Administrative Officer for payroll processing after the HR clerk has manually reviewed and computed the made work hours. The overview of KSU's time management is shown in figure 7.

At the start of regular work hours, all workers are supposed to be present and ready to work. At the end of their allocated working hours, they are supposed to finish their respective work as well.

KSU only allows a grace period of a maximum of 15 minutes until an employee is deemed tardy. It manually performs the measurement of working hours. The HR clerk measures and cross-checks the biometrics scheme and the logbook from each department and college in order to obtain the actual working hours rendered by an employee. She will forward the time sheet reports to the Chief Administrative Officer for payroll processing after the HR clerk has manually reviewed and computed the made work hours. The overview of KSU's time management is shown in figure 7.

Both staff are expected to be available and ready to work at the beginning of normal work hours. They are also expected to finish their respective work at the end of their allotted working hours. 
KSU only provides a maximum grace period of 15 minutes before an employee is found to be tardy. It conducts the estimation of working hours manually. In order to obtain the actual working hours offered by an employee, the HR clerk tests and cross-checks the biometrics scheme and the logbook from each department and college. After the HR clerk has manually checked and measured the work hours generated, she will forward the time sheet reports to the Chief Administrative Officer for payroll processing. Figure 7 illustrates the summary of KSU's time management.

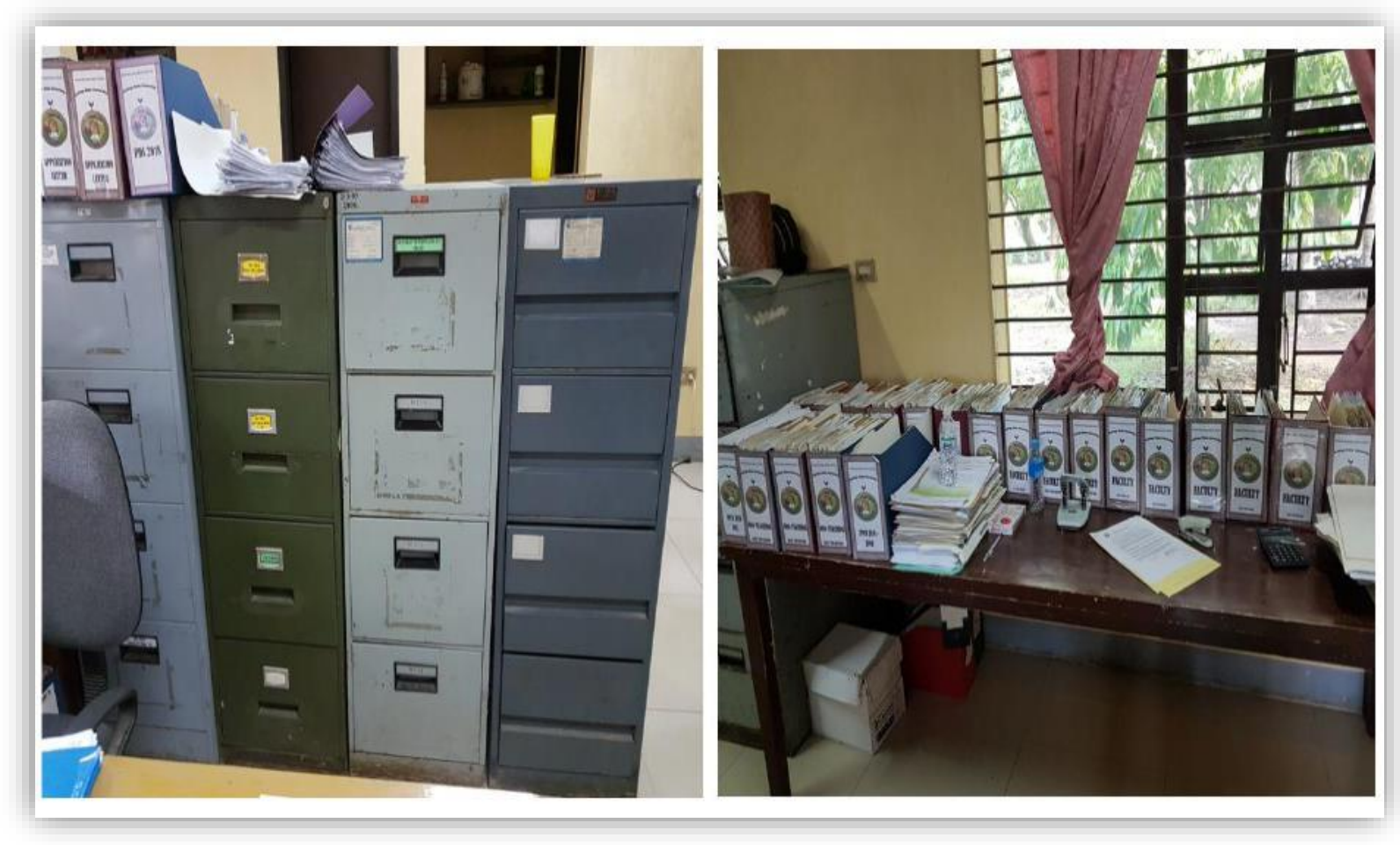

Fig.8: Filing Storage of KSU

Most of their HR processes would be faster if Kalinga State University (KSU) adapts SAP ERP to their system. Retrieving, reviewing, and upgrading applicant(s) records would become simpler in terms of manpower preparation shown in Figure 9. 


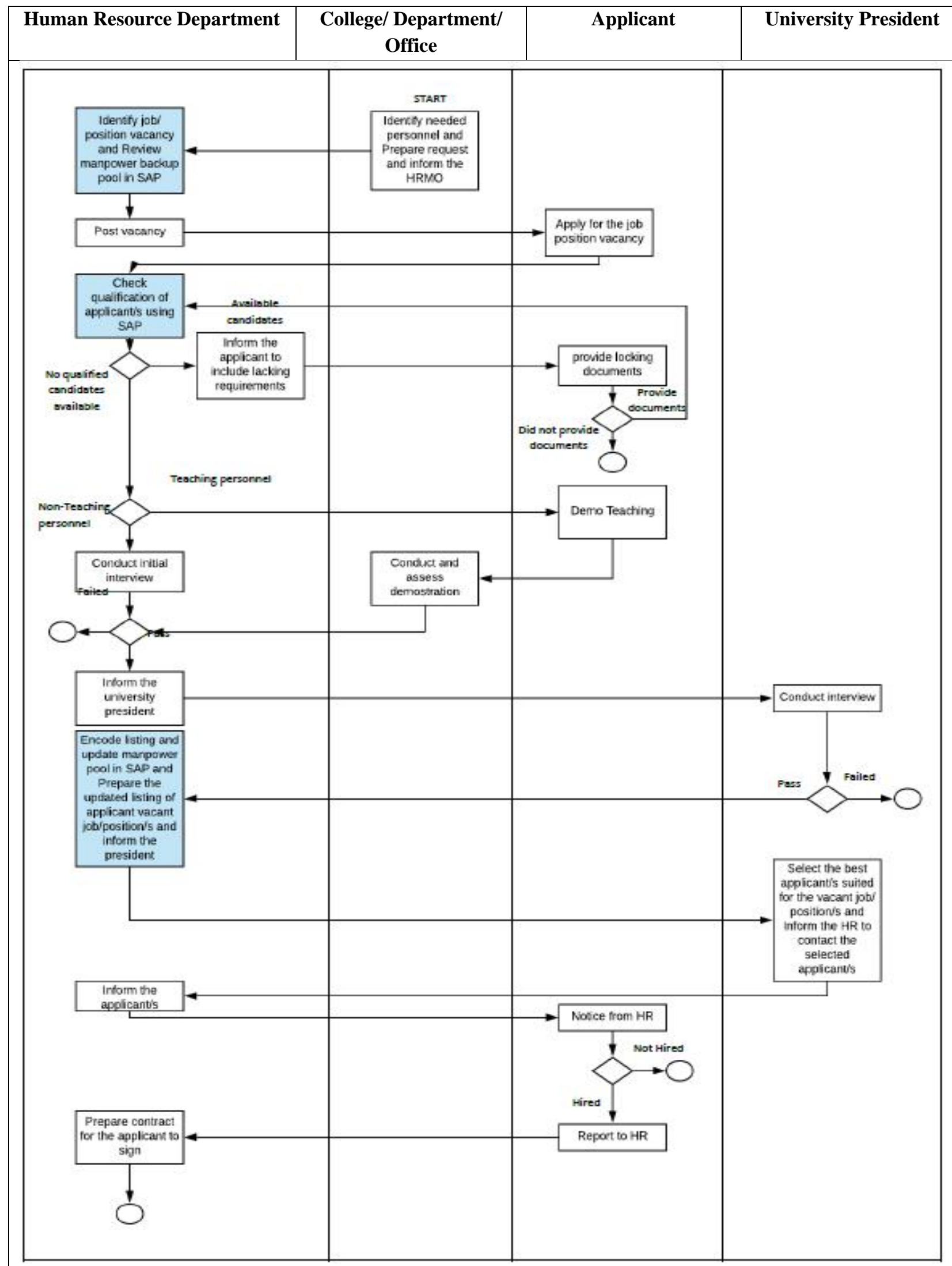

Fig.9: Manpower Planning of KSU (To-Be) 
In Personnel Management, if an upgrade to their records as shown in figure 10 is needed, there will be no more hustle in locating or editing employee data.

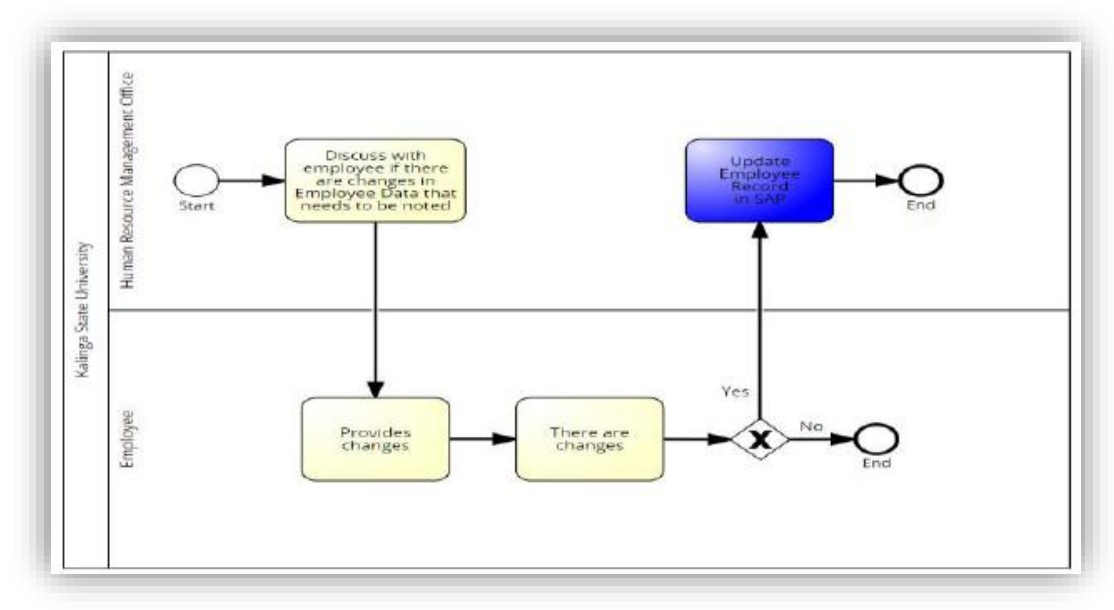

Fig.10: KSU Personnel Management (To-Be)

Upon SAP ERP introduction, manual counting of tardiness, absences and leaves shown in figure 11 will also be eradicated. All you need to do is insert the data into the system and the system will immediately and correctly produce the appropriate reports automatically.

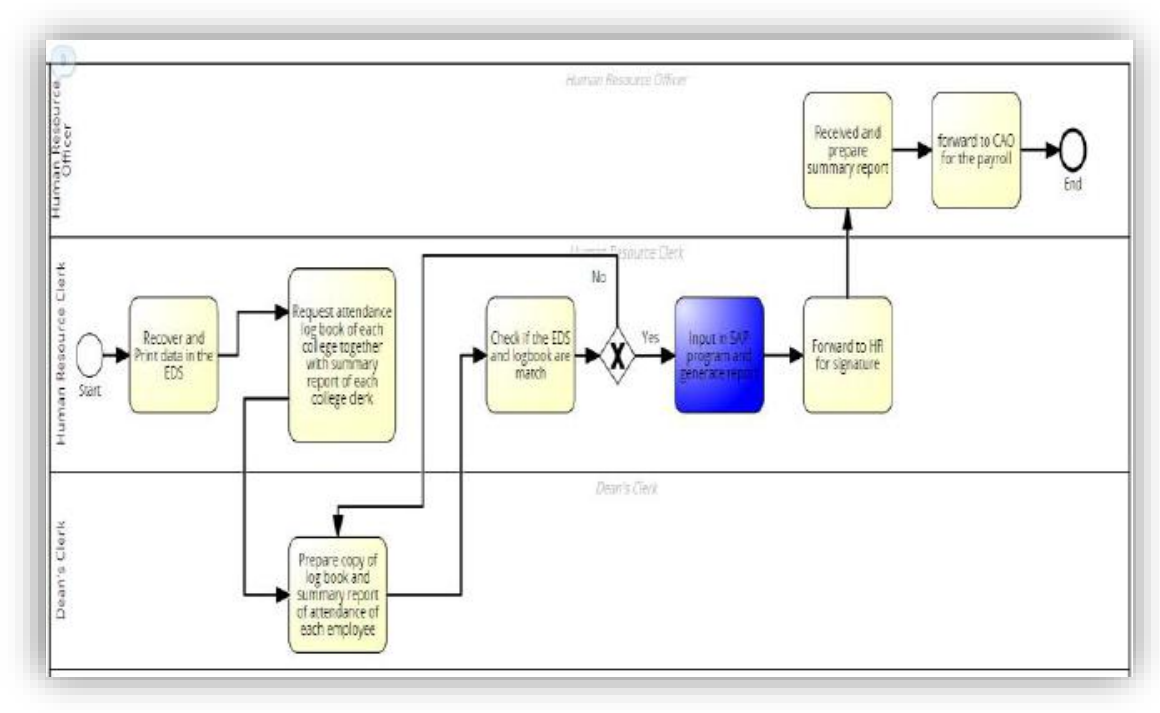

Fig.11: KSU Time Management (To-Be)

The purpose of this paper is to configure and apply the SAP HR module specific to these two components: management of organizations and management of workers. Due to the complexity and the incorporation of FICO modules, the fields of personnel planning and development, time management and payroll accounting are not included in this report.
Structure for Organization. The HR frameworks that reflect the organizational situation within the business must be considered in order to be able to configure the defined HR modules. This means that the three primary structures should start by establishing the HR configuration. The key structures consist of the organizational structure, the structure of the company and the structure of the workers. These structures are important to the success of the work of SAP HR systems ('SAP HCM Master Data Structures', n.d.). 
The foundations of the processing of human capital are these systems. They are often used logically to better organize workers in order to treat others with identical payroll, time management, reporting, and authorization characteristics. Because of that rationale, maintaining suitable control, keenness and vigilance over the use of the said frameworks is crucial and essential for a business.

A full-blown organizational structure includes the company and staff systems to be set up effectively.

An organizational structure should have been up and running and essentially defined before the staff master data of the employees can be entered. This suggests that the data of workers should have been incorporated into the structure. In a corporation, the enterprise structure reflects structured and financial structures and is essentially composed of the company code, the staff area, and the staff sub-area. The personnel structure, on the other hand, shows the relationship between employees and assigns them to certain groups and subgroups of employees.
The organizational chart would be the basis for the three HR systems being configured.

Setup for Enterprise Structure. The structure of the organization consists of the customer, company code, staff area, and sub-area of personnel. The staff region is a particular staff administration body and a subdivision of the company code. On the other hand, the personnel sub-area is a subdivision of the personnel area.

The To-Be business structure of KSU is presented in Figure 12. It shows KSU as the customer and the code of the business. The staff area of KSU includes VPASD, Vice President for Administration, Finance, Planning and Growth, and Vice President for Academic and Student Development (VPASD) (VPAFPD). Management Information System (MIS), Human Resources (HR), Faculties, Finance, Supply, General Services Office (GSO), Registrar's Office, Research and Development (RND), Office of the University President, Legal Counsel and Student Development Services are provided by the Staff sub-area (SDS).

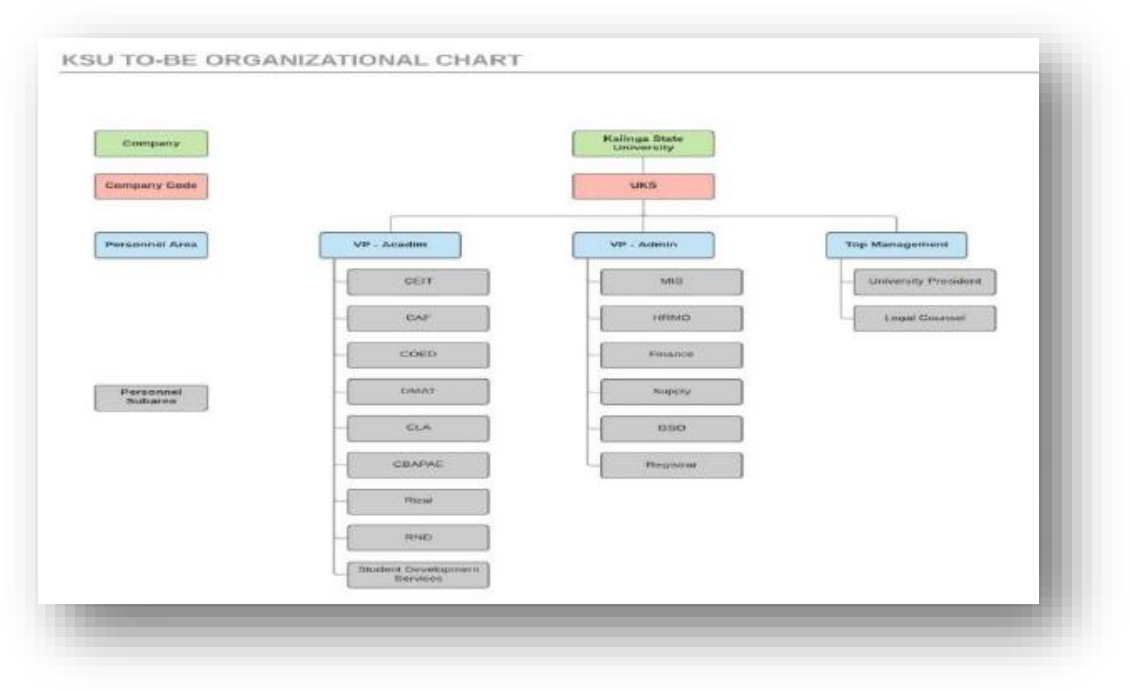

Fig.12: KSU To-Be Organizational Chart

Matchup for Profile. The required and current expertise of each qualification is often considered in order to compare the qualifications and conditions of subjects (persons, candidates, occupations, roles, etc.) against each other. For example, this means that the consumer may compare the credentials of an employee with the requirements of the position an employee holds in order to see how suitable the employee is for this position. In a profile matchup, the user may include an infinite number of items, as shown in figure 13. 


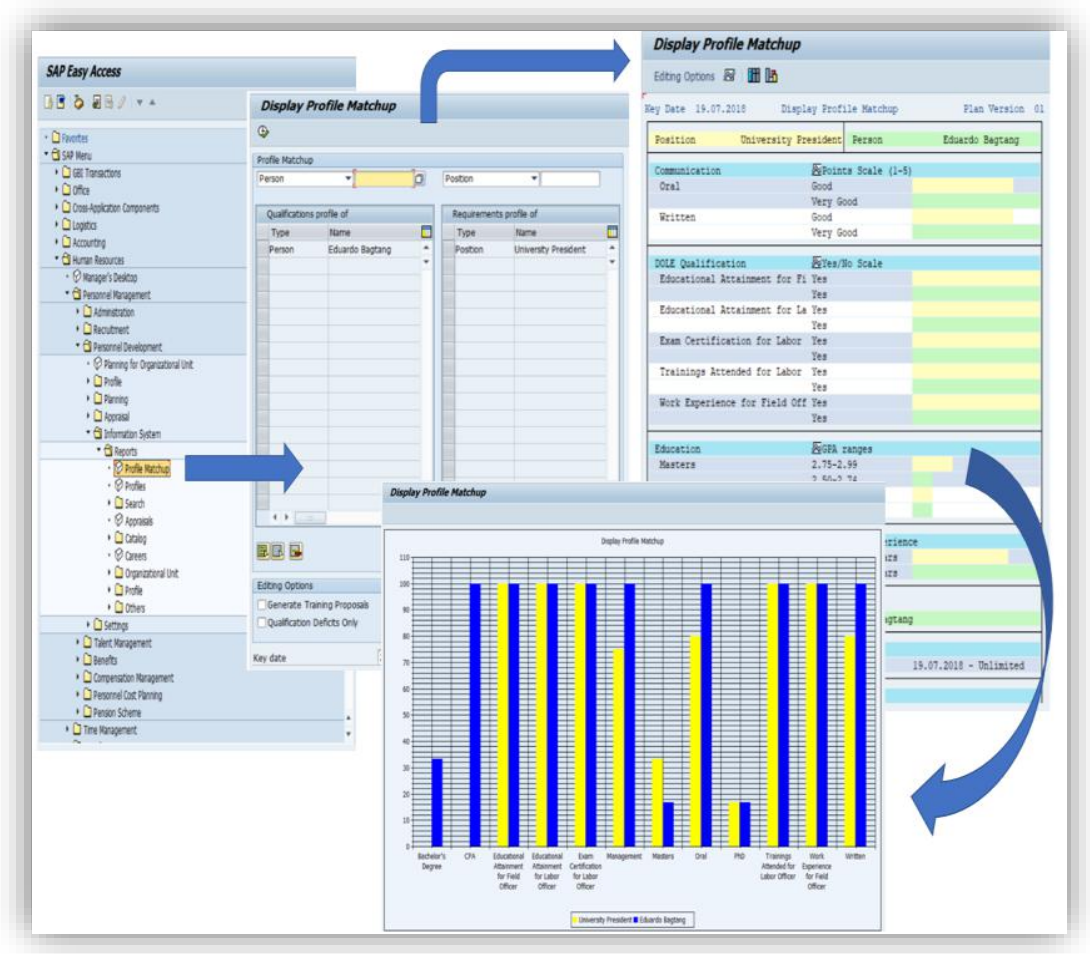

Fig.13: Profile Matchup

Figure 14 shows the result of profile matchup for the IT Program Head position.

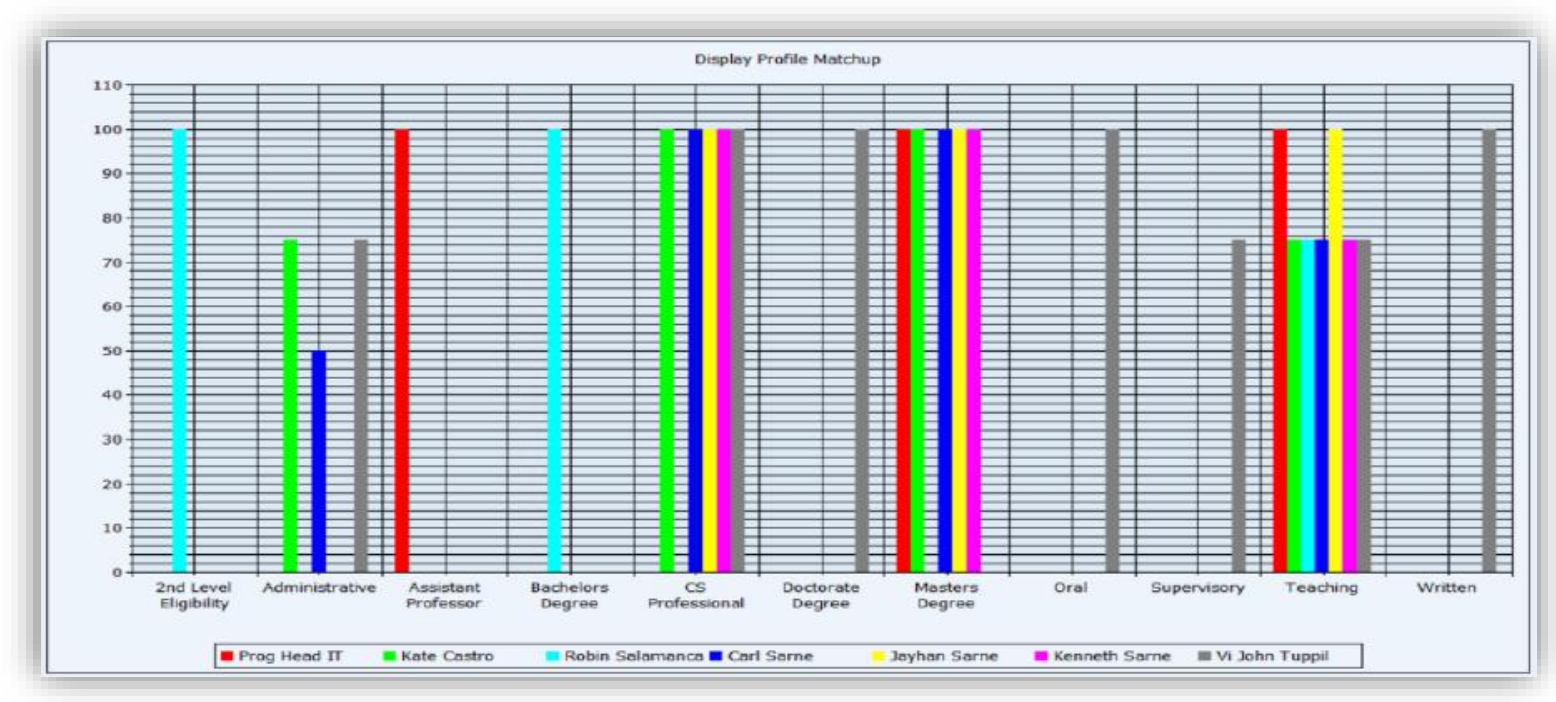

Fig.14: Profile Matchup result for Program Head IT

Succession Preparation is structured to ensure that the supply of trained staff is continuous. Succession planning focuses on the roles that need to be filled (or need to be filled in the future) in an organization since current positions have become vacant or new positions have been established. In addition, succession planning chooses appropriate potential successors for these posts, carefully trains these successors for these posts so that if a vacancy occurs, they can be moved immediately. 
The user may also search for people, candidates, etc that fit the profiles of activity-related items in succession planning.

For each position, potential successors are determined to display a summary of the succession scenarios for all an organizational unit's roles. Choose the organizational unit on the "succession overview" screen, then click on the desired planning criteria. The Succession Overview screen appears after these steps, which also shows the number of potential successors identified for each role.

The displayed information is broken down by the planning requirements. This framework provides an overview of the succession scenarios described as shown in Figure 15, for each position within the organizational unit.

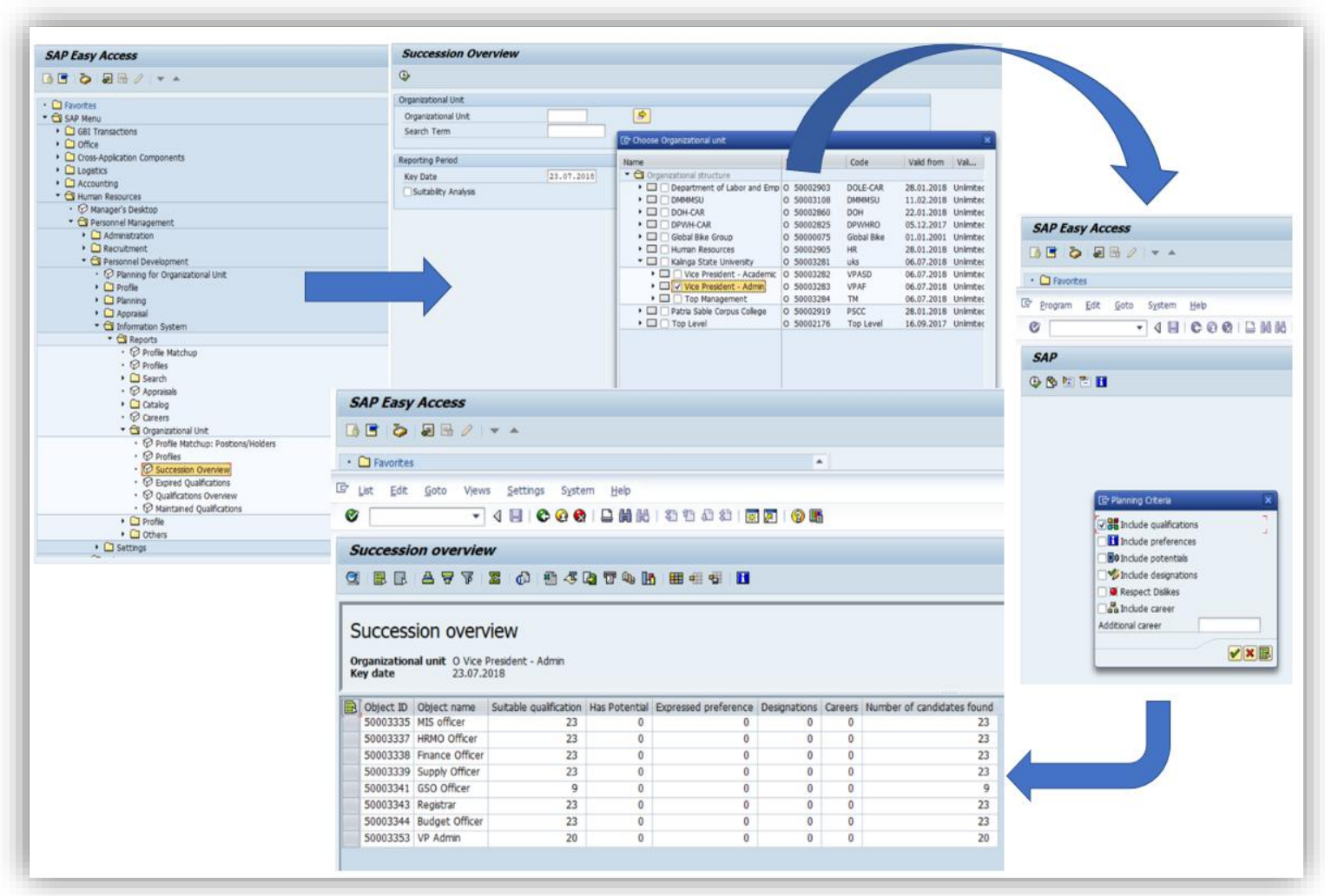

Fig.15: Succession Overview

\section{CONCLUSIONS}

Based on the study's findings, the following conclusions were drawn.

The current set-up of the human resources of KSU is as follows: the HR department of KSU has two (2) employees and there are three (3) main processes, and each of these processes has current ways of facilitating the management of HR data. The College currently has standard procedures for human resources, but they are not yet fully automated and most master data is manually managed and not regularly updated. The university's common issue and difficulty, due to the lack of a centralized tool for handling human resources data, is the accuracy of data that usually results in inefficient reports.

\section{RECOMMENDATIONS}

The researcher suggests, in accordance with the study's findings, the following:

The proposed HR organizational framework should be used to provide an efficient means of handling human data and processes; the implementation of SAP ERP ECC 6.0 should be taken into account by Kalinga State University; financial budgeting and preparation should take place whether or not to adapt SAP ERP ECC 6.0 to ensure that the benefits received equate to the costs to be incurred; In scoping, it is recommended to be extra cautious and maintain an extensive understanding of FI (Financial) and CO (Controlling); A further analysis is recommended for the time management module and accounting payroll modules due to time constraint and complexity; the results on the profile matchup should 
produce top 3 or top 5 if there are multiple qualified candidates in the role and the following considerations should be considered in selecting the top 3 or top 5: length of service and academic achievement; and because the position is multiple qualified candidates and in selecting the top 3 or top 5

\section{REFERENCES}

[1] Anand, T. (2009, April 2). Learn SAP HR/HCM. Retrieved on April 15, 2015, from http://learnsaphr.blogspot.com /2009/04/employee-group-emplzoyee-subgroup.html.

[2] Barker, T. and M.N. Frolick. (2003). ERP implementation failure: A case study. Information Systems Management, pp: 43-49. Retrieved on June 20, 2017, from https: //pdfs.semanticscholar.org/8615/7c69318a73bbaa3d15a0d4a9 cdc1b122231f.pdf.

[3] Beheshti, H. M. (2006). What managers should know about ERP/ERP II. Management Research News, 29(4), 184-193.

[4] Chang, H.H., H.W. Chou, C.P. Yin and C.I. Lin. (2011). ERP Post-Implementation Learning, ERP Usage and Individual Performance Impact. PACIS 2011 Proceedings.

[5] Creating an Organizational Structure. Retrieved on April 1, 2014, from http://saphrcompendium.files.wordpress.com /2011/11/organizational-structure-configuration.pdf.

[6] Develop and empower your people with SAP HR software. Retrieved on September 8, 2014, from https://www54. sap.com/solution/lob/hr.html.

[7] ERP - enterprise resource planning. Retrieved on August 18, 2016, from http://www.webopedia.com/TERM/E/ERP.html.

[8] ERP Implementation at Nestle. Retrieved on August 20, 2016, from http://www.uwosh.edu/faculty_staff/wresch/ ERPNestle.htm.

[9] Ejaz Ali, Tahir Saeed, Irshad Ahmed Soomro and M. Rehan Aslam. (2015). Human Resource Information System: Role in HRM Practices and Organizational Performance. Retrieve on August 17, 2016, from http://waset.org/pdf /books/?id=19623

[10] Everdingen, Y. v., Hillegersberg, J. v., \& Waarts, E. (2000). Enterprise resource planning: ERP adoption by European midsize companies. Retrieved on August 8, 2015, from ACM Digital Library: http://dl.acm.org/ citation.cfm?id=332051.332064\& coll=DL\&dl=ACM.

[11] Expert lists benefits of ERP. (2008, February 19). Retrieved on July 8, 2014, from http://www.thehindu. com/todays-paper/tpbusiness/expert-lists-benefits-of-erp/article1204484.ece.

[12] Free SAP HR/HCM Training. Retrieved on March 14, 2014, from http://www.guru99.com/sap-hcm.html.

[13] Grabski, S.V., S.A. Leech and P.J. Schmidt. (2011). A review of ERP research: A future agenda for accounting information systems. Journal of Information Systems; Volume 25, pp: 1116.

[14] Hariyoga, H., \& Sexton, R. J. (2009). The Rise and Fall of Tri Valley Growers Cooperative. Retrieved on August 22, 2015, from

http://ageconsearch.umn.edu/
bitstream/56923/2/SextonTVG.pdf.

[15] Harrison, J. L. (2004). Motivations for enterprise resource planning (ERP) system implementation in public versus private sector organizations. (Ed.D., University of Central Florida). ProQuest Dissertations and Theses,. (305080817).

[16] Hermie Luquingan Masaspet (2014). Human Resources (HR) Configuration Plan for the Implementation of SAP ERP System in Acestar Solutions and Trading, Inc. Baguio City, Philippines.

[17] Hong, V. (n.d.). ASAP- Accelerated SAP. Retrieved from http://classes.ischool.syr.edu/ist600erp/best/doc/best_asap.pdf

[18] IT management expert sheds light on Jollibee's \#ChickenSad. Retrieved on August 20, 2016, from http://www.gma network.com/news/story/374434/money/companies/itmanagement-expert-sheds-light-on-jollibee-s-chickensad.

[19] Julia E. Houh and James H. Dulebohn. (2013). Shared leadership in enterprise resource planning and human resource management system implementation. Human Resource Management Review 23 114-125.

[20] Kirby Building Systems company. Retrieved on November 23, 2016, http://www.kirbyinternational.com/about-us/companyprofile.html\#sthash.tjcxfjGq.dpuf

[21] Kumar, N. (n.d.). Overview of ERP Human Resources Module. Retrieved on September 28, 2015, from http://www. slideshare.net/Narendra124/overview-of-erp-humanresources-module.

[22] Leo Zornada NSc., Tamara Bertok Vekavrh MSc.. (2005). Implementing ERP System in Higher Education Institutions.

[23] Maryam Shahzadi, Muhammad Shoaib and Rab Nawaz Lodhi. (2014). Impact Study of Enterprice Resource Planning (ERP) in HRM Practices.

[24] Mehlinger, L. (2006). Indicators of Successful Enterprise Technology Implementations in Higher Education Business Morgan State Morgan State University. PhD Thesis.

[25] Murphy C.. (2004). ERP: The Once and Future King of Campus Computing. Campus technology. Syllabus Media Group. Retrieved from: http://www.campustechnology.com /article.asp?id=8868 [20.1.2005]

[26] Musil, J., \& Hoeliner, R. (2009). Overview of the new ASAP Methodology for Implementation 7.x and ASAP Business Add-Ons. Retrieved on August 10, 2016, from http:// www.sdn.sap.com/irj/scn/go/portal/prtroot/docs/library/uuid/1 026829e-7169-2d10-05b6b5dd7042d446? overridelay out=true \&48438641495058.

[27] Nohria, N. and Gulati, R. (1996). Is slack good or bad for innovation? Academy of Management Journal,39, 245- 64.

[28] Nah, F., \& Delgado, S. (2006). Critical success factors for enterprise resource planning implementation and upgrade. Journal of Computer Information Systems, 46(5), 99.

[29] Novell Unified Delivery Process. (2009). Retrieved on July 8, 2015, from http://www.novell.com/docrep/2009/10/ novell_unified_elivery_process_overview_070309_en.pdf.

[30] Organizational Structures and Data Model. Retrieved on 
March 2, 2014, from http://www.mmrs.state.ms.us/ imported/docs/lib/DFA/MMRS\%20Applications/MAGIC/HC M_PR/20111017\%20HCM_OM_01\%20Organizational\%20S tructures\%20and\%20Data\%20Model.pdf.

[31] Overview of Organizational Management in SAP. Retrieved on March 16, 2014, from http://www.purdue.edu/onepurdue /FIHR/documents/overview_om_objects.pdf.

[32] PO10 Create Organizational Unit Infotypes. (2011, May 4). Retrieved April 1, 2014, from http://osc.nc.gov/ training/osctd/help/Organization\%20Management/BPPs/PO1 0CreateOrganizationalUnitInfotypes.pdf.

[33] Punam Ahlawat.(January, 2016). Human resource management with emerging information system a case study. Volume 3; Issue 1; January 2016; Page No. 349-352. Retrieved from: www.allsubjectjournal.com

[34] Robb, D. (2011). Enterprise ERP Buyer's Guide: SAP, Oracle and Microsoft. Retrieved on August 23, 2015, from http://www.enterpriseappstoday.com/erp/enterprise-erpbuyers-guide-sap-oracle-and-microsoft-1.html.

[35] Samman, M. J. (2010, June 15). ERP-HR Modules, Hands-on Approach. Retrieved on September 29, 2014, from http://www.slideshare.net/EMPOWERMC/erp-hr-moduleshandson-approach-white-paper.

[36] SAP AG (2008). SAP ERP 6.0 SR3 ABAP. Retrieved on March 31, 2014, from http://service.sap.com/erp-inst.

[37] SAP AG (n.d.). Creating Organizational Structure in HCM. Retrieved on March 16, 2014, from http://help.sap.com/ saphelp_erp60_sp/helpdata/en/65/1064407b9b990ae1000000 0a155106/content.htm.

[38] SAP AG (n.d.). Human Capital Management. Retrieved on January 30, 2014, from http://web.calstatela.edu/ faculty/pthomas/CIS301/gbi/09.2_Advanced_ERP_Using_G BI_Casestudy_HCM\%5BLetter\%5D_en_v2.11.pdf.

[39] SAP AG (n.d.). Implement SAP. Retrieved on August 4, 2013, from https://support.sap.com/support-programsservices /methodologies/implement-sap.html.

[40] SAP AG (n.d.). Personnel Administration (PA-PA). Retrieved on March 2, 2014, from http://help.sap.com/printdocu/ core/print46c/en/data/pdf/PAPA/PAPA.pdf.

[41] SAP at a glance: company information. Retrieved on October 1, 2016, from http://www.sap.com/corporate-en/ourcompany/index.epx.

[42] SAP HCM Master Data Structures. Retrieved on January 31, 2016, from http://www.knuzen.dk/enterprise_personnel and_org_structures_in_sap_hcm.htm

[43] SAP HR Module (Human Resources Management System). Retrieved on March 14, 2015, from http://www.erpgreat.com/sap-hr.htm.

[44] SAP HR Module | SAP Human Resource Overview. Retrieved on August 25, 2017, from http://www.erpgreat.com/human /sap-hr-module.htm.

[45] SAP Implementation Proposal for using of ASAP tool. Retrieved on April 3, 2015, from http://www.sapclub.sk /docs/PIS/S4/ASAP\%20proposal_general.doc
[46] Sarkis, J., \& Sundarraj, R. (2003). Managing Large-Scale Global Enterprise Resource Planning Systems: A Case Study at Texas Instruments. Retrieved on August 21, 2013, from http://www.clarku.edu/ jsarkis/abs102.htm.

[47] Schaffry, A. (2012, August 21). A Comparison of Top ERP Providers. Retrieved on August 21, 2014, from http:// en.sap.info/erp-panoramaconsulting-microsoftoracle/ 77983.

[48] Shah, S.I., R.H. Bokhari, S. Hassan, M.H. Shah and M.A. Shah. (2011). Socio-technical factors affecting erp implementation success in pakistan: an empirical study. Australian Journal of Basic and Applied Sciences, pp: 742749.

[49] Sravanthi (2006). Training and Event Management. Retrieved on March 30, 2014, from http://www.sapfunctional.com/HCM/Event/Index.htm.

[50] Supply Chain: Hershey's Bittersweet Lesson. Retrieved on August 20, 2016, from http://www.cio.com/article/ 2440386/supply-chain-management/supply-chain--hershey-sbittersweet-lesson.html

[51] Swarts D, Orgill K.. (2001). Higher Education ERP: Lessons Learned. Educase Quaterly 2001; 24:20-27.

[52] Tan, C. L. and Nasurdin, A. M. (2011). Human Resource Management Practices and Organizational Innovations: Assessing the moderating role of knowledge management effectiveness. The Electronic Journal of Knowledge Management, 9(2), 155-167.

[53] Unhoch, N. (2010). Hire - PA40. Retrieved on March 12, 2014, from http://www.erptips.com/Samples/ERPtips-SAPTraining-Manual-SAMPLE-CHAPTER-from-PersonnelAdministration.pdf.

[54] Vikas Bansal, Vani Narula. (2012). Enterprise Resource Planning: Driving Human Resource Management; Volume 2, Issue:1; Page No..40-47

[55] What is ERP. Retrieved on August 18, 2016, from https:// www.syspro.com/us/product/what-is-erp/.

[56] Why SAP Skills are so Important. (2011, August 12). Retrieved on September 30, 2016, from http://www. erp4students.eu/Why-SAP-Skills-are-so-Important_100.aspx.

[57] Zhang, B. (2005). ERP Definition - A Systems Perspective. Retrieved on March 12, 2015, from http://www. sysoptima.com/erp/erp_definition.php.

[58] Zornada, L., \& Velkavrh, T. B. (2005). Implementing ERP systems in higher education institutions. Information Technology Interfaces, 2005. 27th International Conference on, 307-313. 